\title{
The influence of mechanical action on felting shrinkage of wool fabric in the tumble
}

dryer

Wei Bao ${ }^{1,2,3}$, Jinsong Shen ${ }^{3}$, Xuemei Ding ${ }^{1,2,4^{*}}$

1. College of Fashion and Design, Donghua University, Shanghai, China;

2. Key Laboratory of Clothing Design \& Technology (Donghua University), Ministry of Education, Shanghai, China;

3. Textile Engineering and Materials (TEAM) Research Group, School of Fashion and Textile, De Montfort University, Leicester, UK;

4. Shanghai International Institute of Design \& Innovation, Shanghai, China

* Corresponding author:

Xuemei Ding, College of Fashion and Design, Donghua University, Shanghai, China.

Email: fddingxm@dhu.edu.cn

Present address: 1882, West Yan an Road, Shanghai, China

\section{Abstract}

Felting shrinkage of untreated wool fabric occurs easily during tumble drying. Mechanical action applied on fabrics plays a significant part in felting shrinkage of wool fabric. In general, the more severe the mechanical action of a washing or drying machine, the more rapid is felting shrinkage. However, both the degree of mechanical action applied on fabric and the type of mechanical action could influence felting shrinkage of untreated wool fabric.

In the current study, fabric movement and felting shrinkage of untreated wool fabric at different rotation speeds of the drum in a tumble dryer under no heating condition were studied. Based on the different fabric movements at different rotation speeds of the tumble drum, the extent of impact force and rubbing force at different rotation speeds were assessed through their ranking. The total mechanical action applied on the fabric was expressed by the percentage of thread removal of "thread removal fabric" during drying process. The results showed that lowest mechanical force on fabrics could be achieved when the higher rotation speed of the drum was used for drying wool fabrics in tumble dryers, and it could prevent wool felting shrinkage. It was also found that falling of the fabric followed by impact to the drum wall caused less felting shrinkage than sliding with rubbing between fabrics. Therefore, falling movement of fabric could be a potential method to dry wool fabric in drying machines without causing severe 
felting shrinkage.

Key words: wool fabric, felting shrinkage, mechanical force, fabric movement, impact force, tumble dryer

\section{Introduction}

Domestic tumble dryers are popular for drying garments, especially during winter or bad weather conditions. ${ }^{1}$ However, felting shrinkage of wool fabric occurs easily during laundering and drying in tumble machines. Felting is the process of progressive entanglement of the fibers in an assembly, occurring as a result of persistent rootward migration of fibers due to the differential frictional effect (D.F.E.) of scale-configured wool fibers. ${ }^{2}$

There have been many theories on wool felting mechanism. ${ }^{3}$ The popular Shorter's explanation described that felting shrinkage is due to the existence of differing degrees of constraint ("partial entanglement" and "complete entanglement") along the length of any one fiber and D.F.E.. ${ }^{4,5}$ As described, ${ }^{3}$ "a casual disturbance could cause fiber creep to diminish the length between the entanglements so that there would be a tightening up. In the other case, casual disturbances could increase the length of fiber between the two entanglements causing loops to form in the fiber (because a fiber is not rigid like a rod)." The essential conditions for felting to take place are (1) possession by the fiber of a scale structure, (2) moisture and (3) mechanical action. ${ }^{3}$

During tumble drying, mechanical action caused by the rotating drum plays a significant part in felting shrinkage of wool fabric. Many researchers explored the relationship between severity of mechanical action and felting shrinkage of wool fabrics in washing machines, and found that the more severe the mechanical action acting on wet wool, the more rapid the felting shrinkage. Within certain limits, the felting shrinkage of wool fabric increases with the increase of the agitator speed for the agitator washing machine. ${ }^{6}$ An increase in speed of the agitation paddle in the washing machine has two effects: the increase of the mechanical force upon the samples at each impact, and the increase of the frequency of impact. ${ }^{6}$ The rate of felting also varies considerably in different types of washing machines and it was usually contributed to the different degrees of mechanical action. ${ }^{7-9}$ For example, it was believed that the impeller may be "severe" in their action, but the rotating drum is "gentle", thus, the rate of felting of untreated wool fabric may be much higher in impeller-type washing machines than that in drum-type machines. ${ }^{9}$ However, mechanical forces applied on the fabric during 
tumble rotating of the drum or during rotating of the impeller are very complicated, and the different influences caused by the different types of mechanical force were usually overlooked.

In addition, in most previous studies of the effect of mechanical action on felting shrinkage of wool fabric, the severity of mechanical action in the washing machines had not been measured. In other words, variation in rotation speed of machine producing a more severe washing action was not adequately confirmed to be related to more actual mechanical force on fabrics. ${ }^{10}$ Wei et al. characterized mechanical action at different rotation speeds of drum in the tumble dryer. ${ }^{11}$ It was found that with increasing rotation speed of the drying drum, the mechanical action decreases. ${ }^{11}$ However, the range of rotation speed of the tumble dryer studied was limited.

The current study focused on the influence of the mechanical action on felting shrinkage of untreated wool fabric. The movements of fabric at different rotation speeds of the rotating drum were investigated. Furthermore, mechanical actions applied on the fabric at different movements were compared. The total mechanical actions at different rotation speeds were determined by measuring the extent of the removed threads at the outer edges of thread assemblies in woven fabric during tumble drying. Finally, the felting shrinkages of wool fabric at different mechanical actions in the tumble dryer were assessed and analyzed. The present study makes contribution to the knowledge of drying programs of wool fabric in a tumble dryer to prevent felting shrinkage.

\section{Experiment Details}

\subsection{Wool samples preparation}

$100 \%$ wool fabric used ${ }^{12}$ was made from $19.5 \mu \mathrm{m}$ merino wool without shrinkresist treatment. The fabric was weft-knitted using 12 gauge flat knitting machine into plain fabrics. The samples of wool fabric were prepared and made to double layers with a size of $300 \mathrm{~mm}$ x $400 \mathrm{~mm}$. The marked size for measurement of fabric dimension was $220 \mathrm{~mm}$ x $300 \mathrm{~mm}$. According to Test Method - TWC - TM309 Performance of Domestic Tumble Driers for "Hand Wash" Wool Products, all fabric samples were relaxed by the relaxation procedure, i.e. being soaked in water at $40^{\circ} \mathrm{C}$ for 30 minutes and then twice at $20^{\circ} \mathrm{C}$ for 2 minutes followed by flat drying. After flat drying, the fabric samples were conditioned at the standard atmosphere of $65( \pm 3) \% \mathrm{RH}$ and $20( \pm 2){ }^{\circ} \mathrm{C}$ for at least 24 hours.

Two wool fabric samples with wool fabric ballast, sufficient to make up the total fabric weight at $2.00( \pm 0.01) \mathrm{kg}$, were soaked in water in the same way as the relaxation 
process. This simulated the hand-washing procedure. After soaking, the moisture content of all fabric load was controlled to be $60.0( \pm 2.5) \%$ by spinning in a Haier topload washer. ${ }^{12}$ The moisture content of fabric determined in the current study is the ratio of the mass of water to mass of wool fabric that was conditioned at the standard atmosphere.

\subsection{The controlled parameters of the drying procedures}

In order to investigate the effect of mechanical action on the felting shrinkage of wool fabrics, tumble rotation of fabric samples at varying rotation speeds of the drum were carried out under the room temperature (around $20^{\circ} \mathrm{C}$ ). The drying programs of wool fabrics in the tumble dryer at room temperature and their corresponding parameters are shown in Table 1. The tumble dryer used in the study was a modified domestic thermoelectric air-vented dryer (GDZ10-977, Haier Co. Ltd, China) with adjustable parameters. ${ }^{12,13}$ The drum radius of the tumble dryer is around $32.5 \mathrm{~cm}$. At different rotation speeds of the drum, fabric movements varied. In order to compare the mechanical action applied on fabric samples at each cycle of fabric movement, the number of fabric movement cycles was kept the same. Therefore, the fabric drying at room temperature (around $20^{\circ} \mathrm{C}$ ) was stopped when the number of fabric movement cycles reached around 3800 under different drying programs. The moisture content of all wool fabric samples after the completion of drying programs was reduced from $60 \%$ to around $55 \%$.

Table 1 The drying programs of wool fabrics in the tumble dryer at room temperature and their corresponding parameters

\begin{tabular}{cccccccc}
\hline Drying & $\begin{array}{c}\text { Heater } \\
\text { power } \\
\text { programs }\end{array}$ & $\begin{array}{c}\text { Rotation } \\
\text { speed of } \\
\text { drum } \\
( \pm 2 \mathrm{rpm})\end{array}$ & $\begin{array}{c}\text { Rotation } \\
\text { speed of } \\
\text { fabric } \\
\text { movement } \\
( \pm 2 \mathrm{rpm})\end{array}$ & $\begin{array}{c}\text { Total time } \\
\text { of drying } \\
(\mathrm{min})\end{array}$ & $\begin{array}{c}\text { Number } \\
\text { of fabric } \\
\text { movement }\end{array}$ & $\begin{array}{c}\text { Initial } \\
\text { moisture } \\
\text { content } \\
(\%)\end{array}$ & $\begin{array}{c}\text { Air } \\
\text { flow } \\
\text { velocity } \\
(\mathrm{m} / \mathrm{s})\end{array}$ \\
\hline 1 & & 17 & 50 & 77 & & & \\
2 & 0 & 34 & 54 & 70 & $3800 \pm 50$ & $60.0 \pm 2.5$ & 0 \\
3 & & 50 & 55 & 70 & & & \\
\hline
\end{tabular}

Notes: (1) Fabric drying at room temperature $\left(19 \pm 3^{\circ} \mathrm{C}\right)$ was stopped when the number of fabric movement cycles reached around 3800 under different drying programs. (2) Initial moisture content means moisture content of the fabric samples before drying programs. (3) Final moisture content of wool fabrics after these drying programs was reduced from $60 \%$ to around $55 \%$. (4) The exhaust fan was set to not work. 


\subsection{Assessment of wool fabrics}

In order to understand the relationship between mechanical action and felting shrinkage in a tumble dryer, the fabric movements at different rotation speeds of the drum in the tumble dryer were observed, the degree of total mechanical action during tumble rotating and dimensional change of wool fabric were determined.

\subsubsection{The video capture of different movements of wool fabrics at varying rotation} speeds of the drum in the tumble dryer

During the drying process of wool fabric at varying rotation speeds of the drum in the tumble dryer, a camera (Fujifilm, X-A10) was placed in front of the transparent door of the tumble dryer to capture the movement of fabric during tumble rotating. The fabric sample to be traced was dyed yellow to differentiate it from others during the monitoring of fabric movement (Figure 1). Two-dimensional tracks of fabric movement during tumble rotation were captured. Three key positions in each cycle of fabric motion were identified by analysis of recorded track of fabric movement from the observation of 5 cycles of fabric movement. The three key positions are (a) the starting position at which the fabric started to be projected after impacted by the lifter, (b) the highest position to which the fabric was projected, and (c) the impact position at which the fabric hit on the drum wall. Based on a rectangular coordinate system with the position of the drum center as the origin point, medians of coordinate $\mathrm{x}$ and $\mathrm{y}$ of the observation of 5 cycles of fabric movement were identified as the three key positions of the tracer fabric in the tumble drum.

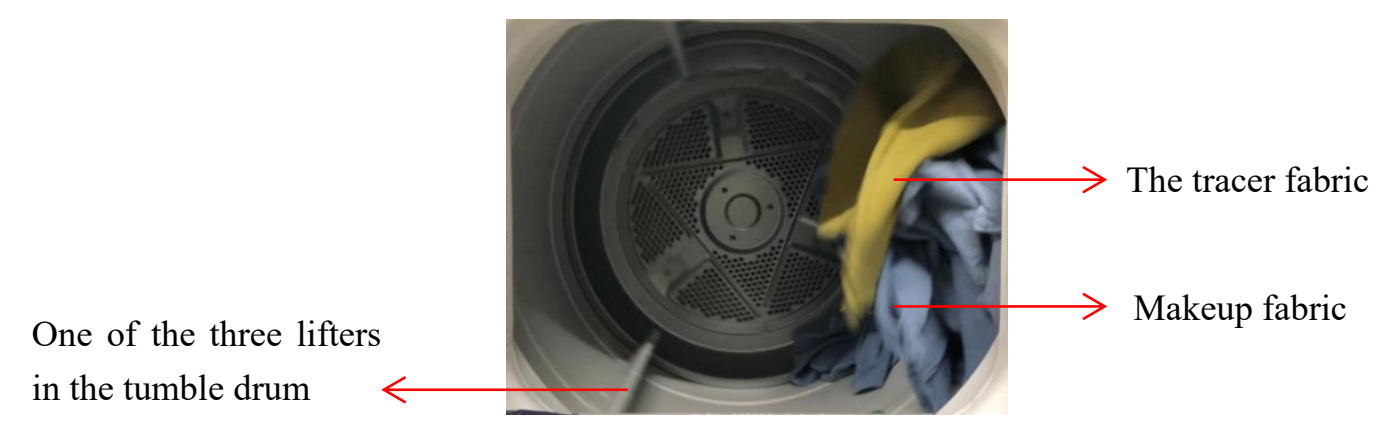

Figure 1 Fabric movement captured in the process of drum rotating in the tumble dryer

\subsubsection{The degree of total mechanical action applied on fabrics during tumble rotation}

Mechanical action on fabrics during the tumble drying process could be influenced by the speed of tumble rotation. The degree of total mechanical action on fabrics was determined by the percentage of thread removal of a specific polyester woven fabric ${ }^{14}$, which was called "thread removal fabric" in the current work. The threads at the fringes 
of the thread removal fabric are loose and thus they are easily to be removed as mechanical action is imparted on the fabric during tumble drying. The measuring method of the thread removal from the polyester fabric (Figure 2) was carried out based on EMPA 304 (IEC PAS 62473-2007). The thread removal fabric was fixed on the center of the wool fabric sample by stitching. Considering that the number of threads of the fabric was hard to count, the lengths across the original and remaining woven structure of the fabric could be a substitute for measurement to calculate the percentage of thread removal. In each test, 5 pieces of the thread removal fabric were used. The percentage of thread removal of the fabric was calculated using Equations (2)-(4) with reference to IEC PAS 62473-2007.

$$
\begin{aligned}
& A_{\text {warp }}=\frac{T_{\text {warp }, o}-T_{\text {warp }, r}}{T_{\text {warp }, o}} \cdot 100 \% \\
& A_{\text {wef } t}=\frac{T_{\text {weft }, o}-T_{\text {weft }, r}}{T_{\text {weft }, o}} \\
& A=\frac{A_{\text {warp }}+A_{\text {weft }}}{2}
\end{aligned}
$$

Where $A_{\text {warp }}$ is the percentage of warp thread removal from the whole "thread removal fabric", $A_{\text {weft }}$ is the percentage of weft thread removal, $A$ is the percentage of thread removal; $T_{\text {warp,o }}$ is the average length across the original warp woven structure, and $T_{\text {warp }, r}$ is average length across the remaining warp woven structure; $T_{\text {weft,o }}$ is average length across the original weft woven structure, and $T_{\text {weft, } r}$ is average length across the remaining weft woven structure.

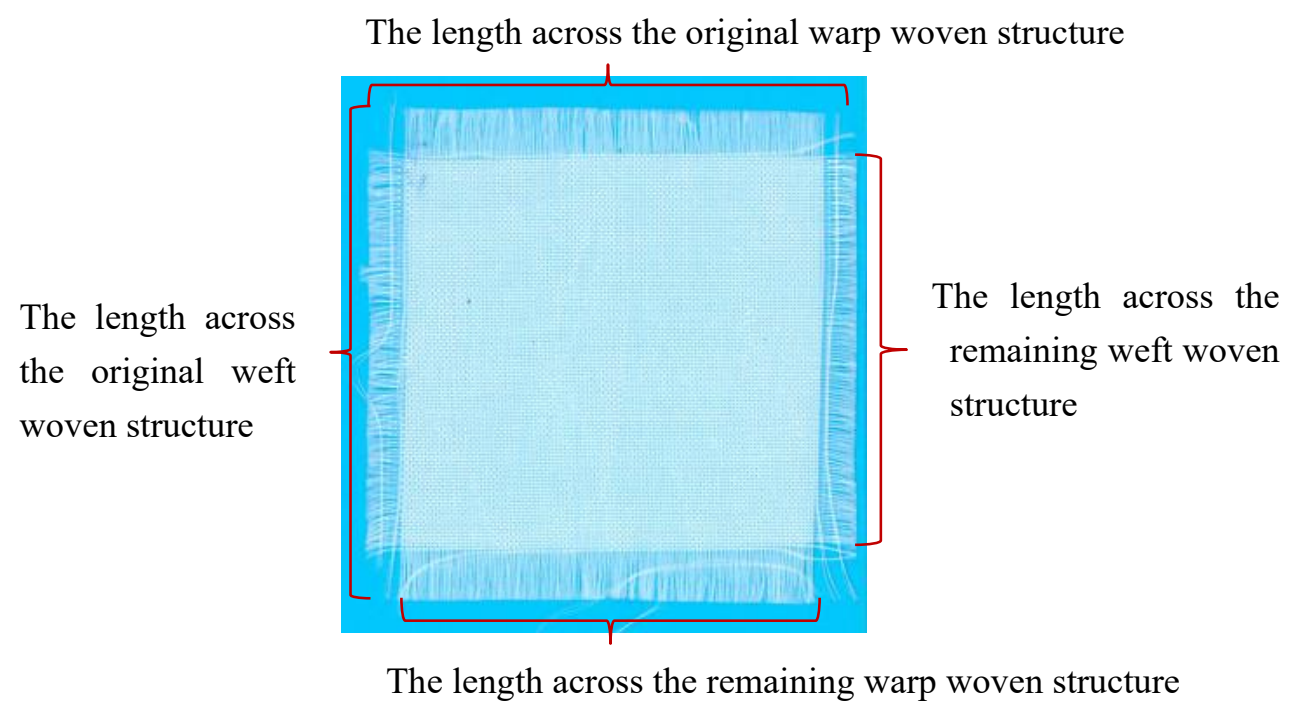

Figure 2 The thread removal fabric that was used as a measure of the total mechanical action on the fabric in the tumble dryer 
The "thread removal fabric" has been used to measure the severity of mechanical action of washing machine in the previous study. ${ }^{14,15}$ In order to check the suitability of "the thread removal fabric" to be used as a measure of the total mechanical action on the fabric in the tumble dryer, the percentage of thread removal at different drying times: 10, 20, 30 and 40 min was measured under the drying procedures as shown in Table 2.

Table 2 Tumble drying programs of experiments used to measure the percentage of thread removal of fabric

\begin{tabular}{lcccc}
\hline Total time of & Heater power & Rotation speed of \\
drying $(\mathrm{min})$ & $( \pm 10 \mathrm{~W})$ & drum $( \pm 2 \mathrm{rpm})$ & Air flow & Initial moisture \\
& & 48 & 5.5 & content $( \pm 2.5 \%)$ \\
\hline $10,20,30,40$ & 3000 & $40.5 \mathrm{~m} / \mathrm{s})$ & 60 \\
\hline
\end{tabular}

\subsubsection{Dimensional change of wool fabric}

The change in length of wool fabric samples in warp direction, called as "length change", was used to characterize dimensional change of wool fabric. It was calculated using Equation (5) based on AATCC Test Method 135-2014 "Dimensional Changes in Automatic Home Laundering of Woven or Knitted Fabrics".

$$
L C=\frac{B-A}{A} \cdot 100 \%
$$

Where $L C$ is length change of fabric samples in percentage, $A$ is original length of fabric sample before washing and drying, and $B$ is length after washing and drying. All of the specimens were measured after being conditioned in the standard atmosphere of $65( \pm 3) \% \mathrm{RH}$ and $20( \pm 2){ }^{\circ} \mathrm{C}$ for at least $16 \mathrm{~h}$.

\section{Results and discussion}

In order to investigate the relationship between felting shrinkage of wool fabric and mechanical action caused by the rotating drum of the tumble dryer, movements of fabric samples and mechanical actions at different rotation speeds of the drum were examined, and length change of wool fabric at different mechanical action in the tumble dryer were studied.

\subsection{Movements of fabrics at varying rotation speeds of the drum}

Rotation speed of the drum affected the fabric movement in tumble machines. According to the captured video of fabric movement in the tumble dryer, the conceptual 
diagrams of these movements of tracer fabric with three key positions are shown in Figure 3 (a)-(d). Except for the case of drum rotation speed at $66 \mathrm{rpm}$, three key positions recorded at drum rotation speeds of $17 \mathrm{rpm}, 34 \mathrm{rpm}$ and $50 \mathrm{rpm}$ are: a) the starting position at which the fabric started to be projected after being impacted by the lifter, b) the highest position to which the fabric was projected, and c) the impact position at which the fabric hit on the drum wall. Although the method of tracking the fabric motion during tumble rotating is not wholly accurate, it could be used to compare the various fabric motions at different rotation speeds in this study.

Figure 3 shows that with increasing rotation speed of the drum from $17 \mathrm{rpm}$ to 66 $\mathrm{rpm}$, the circulated area of fabric movements increased. When the rotation speed of the drum was $17 \mathrm{rpm}$ to $50 \mathrm{rpm}$, the starting position at which the fabric started to be projected after being impacted by the lifter, became higher with increasing the rotation speed of the drum. It was also observed that the fabric sample moved around the corner of the drum when the rotation speed of the drum was $17 \mathrm{rpm}$ (Figure 3 (a)), while at 66 rpm rotation speed of the drum, the fabric sample was adhered to the drum wall and rotated with the drum.

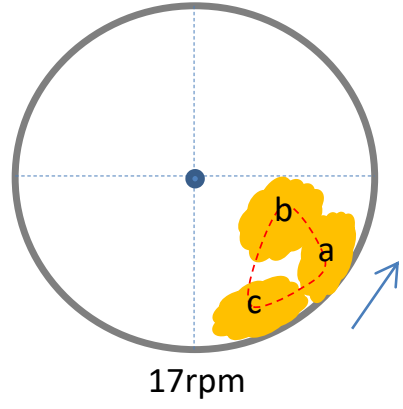

(a)

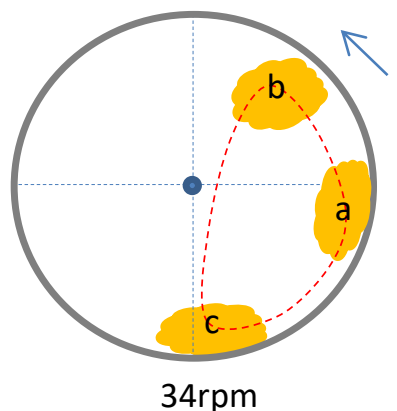

(b)

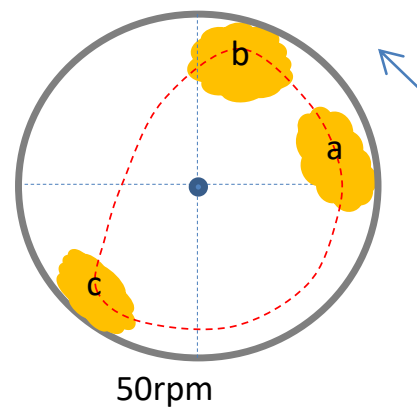

(c)

$\left(c^{\prime}\right)$

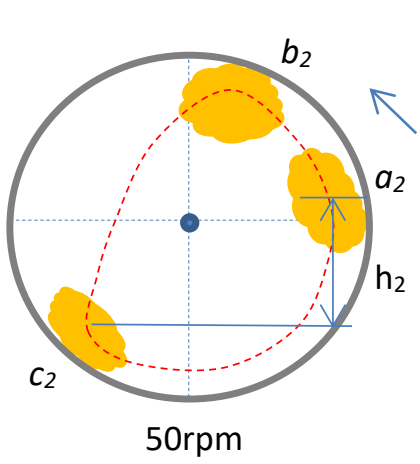

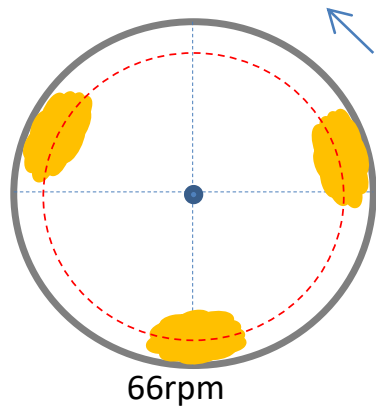

(d)

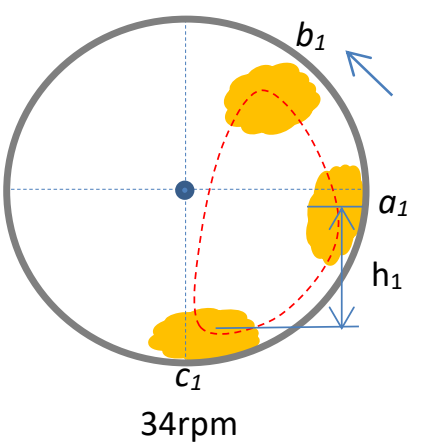

(b')

Figure 3 Conceptual diagram for fabric movements at different rotation speeds 
In order to analyze the effect of the rotation speed of the drum on fabric movement in a simplified way, the fabric sample could be regarded as a particle. The effect of rotation speed of the drum on the movement of a fabric sample when only single fabric was in the tumble dryer could be theoretically analyzed. If the mass of this fabric sample is $\mathrm{m}$, gravitational acceleration is $\mathrm{g}$, the rotation speed per second of the drum is $\mathrm{n}$, and the circular radius of the drum is $r$, then the gravity of the fabric sample would be $\mathrm{mg}$, and the centripetal force required for circular motion would be $\mathrm{m} \cdot(2 \pi \mathrm{n})^{2} \cdot \mathrm{r}$. When $\mathrm{mg} \leq$ $\mathrm{m} \cdot(2 \pi \mathrm{n})^{2} \cdot \mathrm{r}$, (i.e. the rotation speed per second of the drum $\mathrm{n} \geq \sqrt{\frac{g}{r}} /(2 \pi)$, the fabric would rotate with the drum. ${ }^{16}$ This could explain the fabric rotation movement when the rotation speed was $66 \mathrm{rpm}$. It should be noted that in practicality, the required rotation speed to make the fabric rotate with the drum is higher than the theoretical calculation $\sqrt{\frac{g}{r}} /(2 \pi)$ because the fabric sample is larger than an actual particle, which means that the effective radius is smaller than the radius of the drum.

The following is the analysis of fabric movement when $\mathrm{n}<\sqrt{\frac{g}{r}} /(2 \pi)$. A rectangular coordinate system was generated based on the position of the center of the drum. Regardless of the air-resistance, the forces applied on the fabric at the fourth quadrant $(I V)$ are shown in Figure 4. According to Newton's second law, the movement of the fabric is determined by the balance of the component of gravity along the tangential direction $(m g \sin \theta)$ and the frictional force $\left(\mu m g \cos \theta+\mu m(2 \pi n)^{2} r\right) .{ }^{17}$ When the fabric moves anticlockwise, the angle $\theta$ will increase, while the frictional force will decrease. If the rotation speed of the drum $\mathrm{n}$ is small, the fabric will accelerate firstly, and then decelerate. When the speed of the fabric decreases to 0 , the fabric could slide backward against the anticlockwise rotation direction of the drum. Then the fabric will be impacted by the lifter, projected into air, and finally the fabric will fall down and impact on the drum wall. This could explain the fabric movement in the drum in the case of rotation speed of $17 \mathrm{rpm}, 34 \mathrm{rpm}$ and $50 \mathrm{rpm}$. 


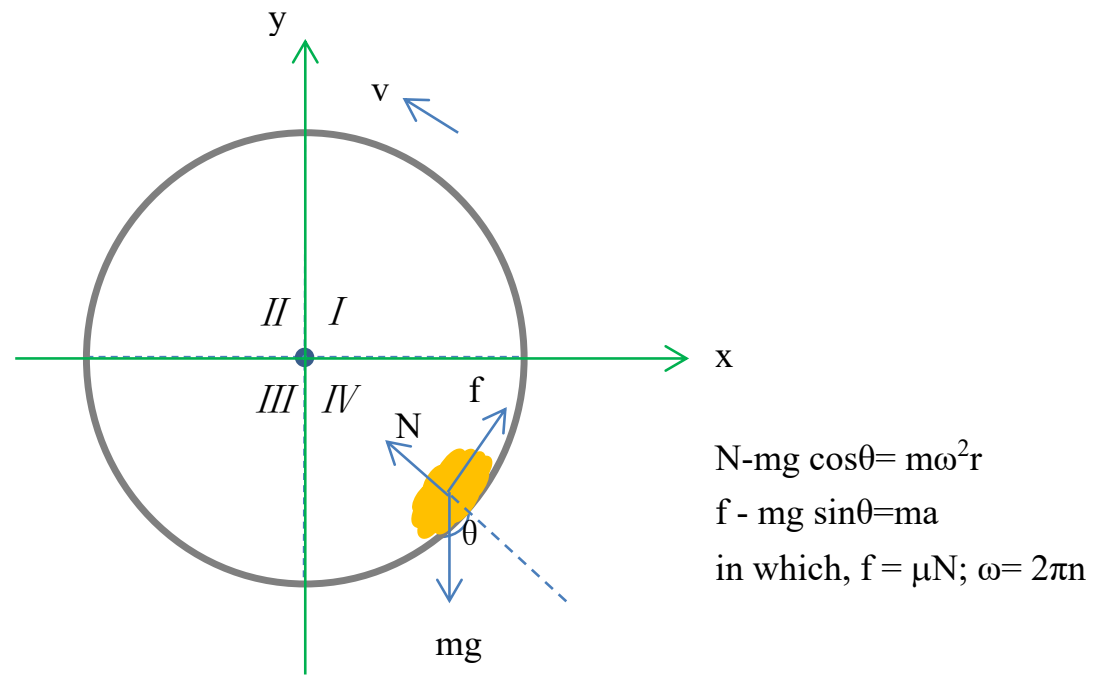

Figure 4 Analysis of forces on the fabric during fabric movement in the drum

(Notes: m: mass of the object; g: gravitational acceleration; $\mathrm{N}$ : the supporting force of the drum wall on the fabric; f: the frictional force of the drum wall against the fabric; $\theta$ : angle of the inclined surface; r: circular radius; $\omega$ : angular velocity; $\mu$ : coefficient of friction; $n$ : the rotation speed of the drum)

\subsection{The mechanical actions at different rotation speeds}

\subsubsection{Total mechanical actions at varying rotation speeds}

The intensity of total mechanical action on the fabric had been determined by measuring the degree of thread removal of "the thread removal fabric" in washing machines in the previous studies. ${ }^{14,15}$ The percentage of thread removal of "the thread removal fabric" was tested at various drying times $(10,20,30,40 \mathrm{~min})$ to check whether this method could be used in the tumble dryer for assessing the extent of mechanical action. Figure 5 shows that with the extension of the drying time, the mechanical action applied on the fabric was accumulated. The percentage of thread removal increased linearly with increasing drying time in the tumble dryer with less than $2 \%$ of standard deviation. Therefore, the percentage of thread removal can be used as a measure of the total mechanical action applied on the wool fabric in the tumble dryer. 


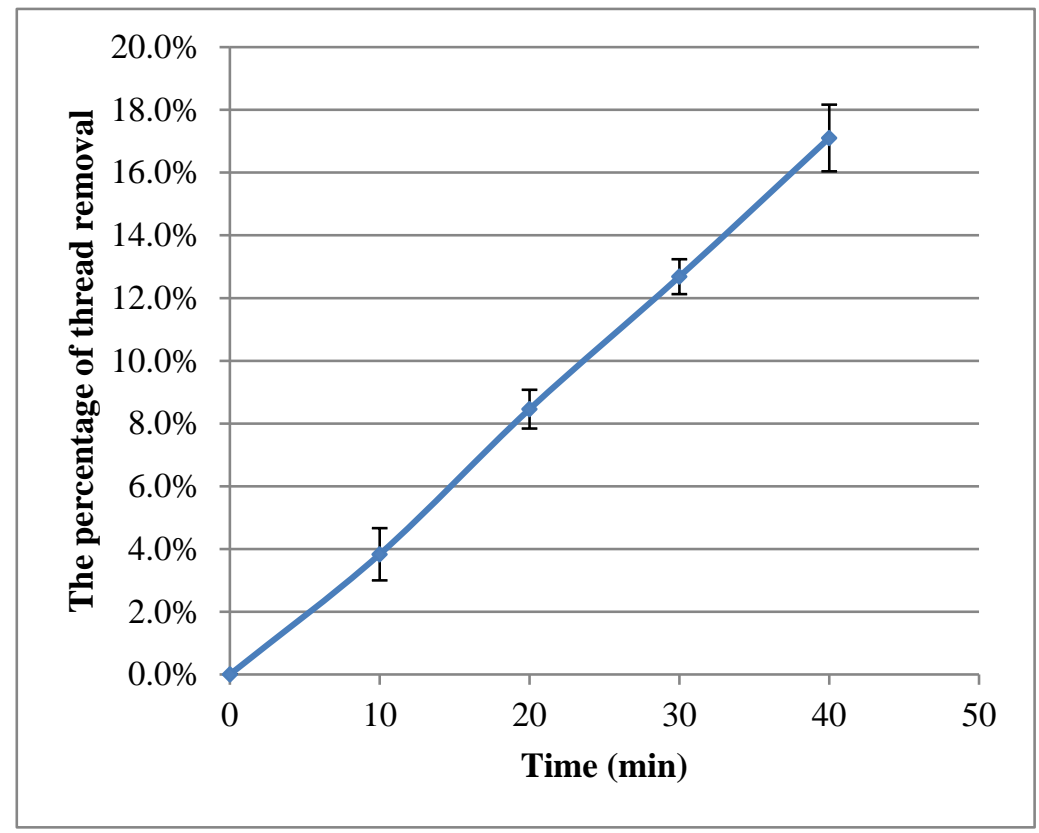

Figure 5 Percentage of thread removal at different drying time at the same rotation speed of $48 \mathrm{rpm}$ in the tumble dryer

Figure 6 shows the relationship between the percentage of thread removal and the rotation speed of the drum. The corresponding parameters for the drying programs are shown in Table 1. The result shows that the total mechanical action experienced by the thread removal fabric increased with increasing the rotation speed of the drum up to 34 rpm, but it decreased when the rotation speed further increased. Mechanical action applied on the fabric at varying rotation speeds depended on the different movements of fabrics. This was analyzed in Sections 3.2.2 to 3.2.4.

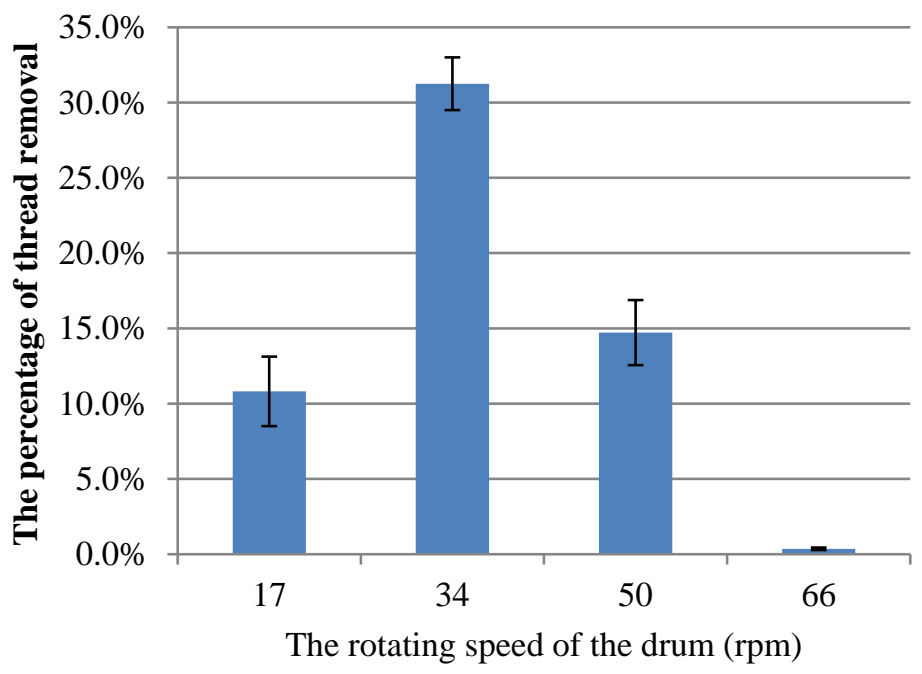

Figure 6 Relationship between the percentage of thread removal and the rotation speed of the drum.

Vertical lines indicate the standard deviations 


\subsubsection{Mechanical actions during tumble rotation}

Under highrotation speed of the drum at $66 \mathrm{rpm}$, the fabric adhered to the wall of the drum and rotated with the drum. Therefore, the fabrics were only subjected to little impact force and little rubbing forces between fabrics or between the fabric and the drum wall. Compared with lower rotation speeds of the tumble drum, the mechanical forces applied on the wool fabric samples at drum rotation speed of $66 \mathrm{rpm}$ could be lowest. Mechanical forces applied on the fabric at $17 \mathrm{rpm}, 34 \mathrm{rpm}$ and $50 \mathrm{rpm}$ rotation speeds during tumble rotating are very complicated. However, the main mechanical forces in the tumble machine considered in this study were impact force between fabric and the drum wall and rubbing force between wool fabrics. ${ }^{18}$ The fabric experiences the greatest mechanical action upon impact after having been projected into the air in the motion of the rotating drum at the normal rotation speed. ${ }^{18}$ It is difficult to measure or calculate the accurate values of impact force and rubbing force applied on the fabric, therefore, the intensity of impact force applied on the fabric and rubbing between fabrics in the cycle of fabric movement at different rotation speeds of the drum were qualitatively analyzed and discussed.

\subsubsection{Impact forces between fabric and drum wall at different rotation speeds}

The impact force applied on the fabric in one cycle of fabric movement at different rotation speeds of the drum were qualitatively analyzed using the empirical formula of the momentum theorem. The tracer fabric could be regarded as a particle. Ignoring air resistance and the influence of other fabric on the tracer fabric, and assuming that the velocity of the fabric after impacting was approximately zero, the amount of impact force can be calculated from the following formula (6) according to the empirical formula of the momentum theorem.

$$
\mathrm{F}=\frac{m v}{t}
$$

Where $F$ is the impact force applied on the wool fabric sample, $m$ is the mass of the fabric sample. $t$ is the time of impacting. $v$ is the velocity of the fabric just prior to the impact on the drum wall.

If the impacting time $(t)$ at $17 \mathrm{rpm}, 34 \mathrm{rpm}$ and $50 \mathrm{rpm}$ rotation speeds and the mass of the fabric $(m)$ of different movements were same, the intensity of impact force depends on the velocity of the fabric sample just prior to the impact on the drum wall (v). According to kinetic energy theorem and law of oblique projectile motion, the 
velocity of the fabric just prior to the impact on the drum wall $(v)$ could be described as the following formula (7):

$$
\mathrm{v}=\sqrt{2 g h+v_{o}^{2}}
$$

In which, $h$ is the height between the position where the fabric sample started to be projected after being impacted by the lifter of the tumble drum (i.e. the position $a_{l}$ in Figure $3\left(b^{\prime}\right)$ or the position $a_{2}$ in Figure $\left.3\left(c^{\prime}\right)\right)$, and the position where the fabric impacted to the drum wall (i.e. the position $c_{1}$ in Figure $3\left(b^{\prime}\right)$ or the position $c_{2}$ in Figure $3\left(c^{\prime}\right)$ ). As shown in Figure $3\left(b^{\prime}\right)$ and $\left(c^{\prime}\right)$, the height $h$ at the drum rotation speed of $34 \mathrm{rpm}\left(h_{1}\right)$ was similar to that at $50 \mathrm{rpm}\left(h_{2}\right)$, which were higher than the height $h$ at $17 \mathrm{rpm}$. That is to say, the height $h$ at different rotation speeds of the drum increased in the following order: the height $h$ at $17 \mathrm{rpm}<34 \mathrm{rpm} \approx 50 \mathrm{rpm}$. $v_{o}$ is the velocity of the fabric sample when it started to be projected. It is not difficult to know that $v_{o}$ at different rotation speeds of the drum increased in the following order: $v_{o}$ at 17 $\mathrm{rpm}<34 \mathrm{rpm}<50 \mathrm{rpm}$. Therefore, according to formula (7), the velocity of the fabric just prior to the impact on the drum wall $(v)$ increased in the following order: $v$ at $17 \mathrm{rpm}<34 \mathrm{rpm}<50 \mathrm{rpm}$. Based on the formula (6), the amount of the impact force at different rotation speeds of the drum increased in the same order.

\subsubsection{Rubbing mechanical force between wool fabrics at different rotation speeds}

Rubbing intensity between fabrics in one cycle of fabric movement was related to the size of the circulated track area of fabric movement during tumble rotating. With decreasing rotation speed of the drum, the circulated area of fabric movement became smaller as shown in Figure 3. Within small area for all fabric movement, the pressure between fabrics and the frequency of fabrics contacting each other could increase, resulting in the increased rubbing intensity between fabrics at lower rotation speeds of the drum at the following order: $66 \mathrm{rpm}<50 \mathrm{rpm}<34 \mathrm{rpm}<17 \mathrm{rpm}$ which was ranked from 1 to 4 . Different mechanical actions in the cycle of fabric movement at different rotation speeds of the drum are ranked in Table 3. Based on the rankings of mechanical actions at various rotation speeds, the influence of mechanical action on the felting shrinkage of wool fabric was discussed in Section 3.3. 
Table 3 Ranking of the magnitude of different mechanical action in one cycle of fabric movement at different rotation speeds of the drum

\begin{tabular}{cccc}
\hline $\begin{array}{c}\text { Rotation speed of } \\
\text { the drum }\end{array}$ & Impacting & $\begin{array}{c}\text { Rubbing } \\
\text { between fabrics }\end{array}$ & $\begin{array}{c}\text { Degree of total } \\
\text { mechanical action }\end{array}$ \\
\hline 17 & 2 & 4 & 2 \\
34 & 3 & 3 & 4 \\
50 & 4 & 2 & 3 \\
66 & 1 & 1 & 1 \\
\hline
\end{tabular}

Note: a. The rankings were ascending orders from " 1 " to "4", i.e. " 1 " was the lowest, and " 4 " is the highest; $b$. The ranking of the degree of total mechanical action was based on the percentage of thread removal of the "thread removal fabric".

\subsection{The dimensional change of wool fabric at different mechanical actions}

The mechanical action caused by the rotating drum plays an important role in felting shrinkage of wool fabric. In general, the more severe the mechanical action of a washing machine, the more rapid is the felting shrinkage, when other factors are held constant. ${ }^{6}$

In order to investigate the relationship between felting shrinkage of wool fabric and the total mechanical action applied on the fabric in the tumble dryer, the percentage of thread removal from the thread removal fabric was used as the measure of the total mechanical action applied on the fabrics. The relationship between felting shrinkage and total mechanical action experienced by the thread removal fabric is shown in Figure 7. Roughly, severe mechanical action caused great felting shrinkage of wool fabric. The length shrinkage of wool fabric at $66 \mathrm{rpm}$ rotation speed of the drum was the lowest due to the lowest mechanical action. However, comparing the mechanical action impacted on the fabrics at $50 \mathrm{rpm}$ and $17 \mathrm{rpm}$ rotation speeds of the drum, the intensity of total mechanical action on the fabric at $17 \mathrm{rpm}$ was slightly lower but the felting shrinkage of the fabric was much higher. That might be because that the felting shrinkage of wool fabrics could be more severe when caused by rubbing mechanical forces rather than impact forces. The similar results from the previous study demonstrated that rubbing can cause severe felting shrinkage in hand scrubbing, ${ }^{5}$ while the impact force that is perpendicular to the fabric does not cause significant felting shrinkage. ${ }^{3,10}$ The other possible reason was that within the cycle of fabric movement, the impacting was applied to the wool fabric instantaneously, while the constant rubbing between fabrics could occur. ${ }^{19}$ 


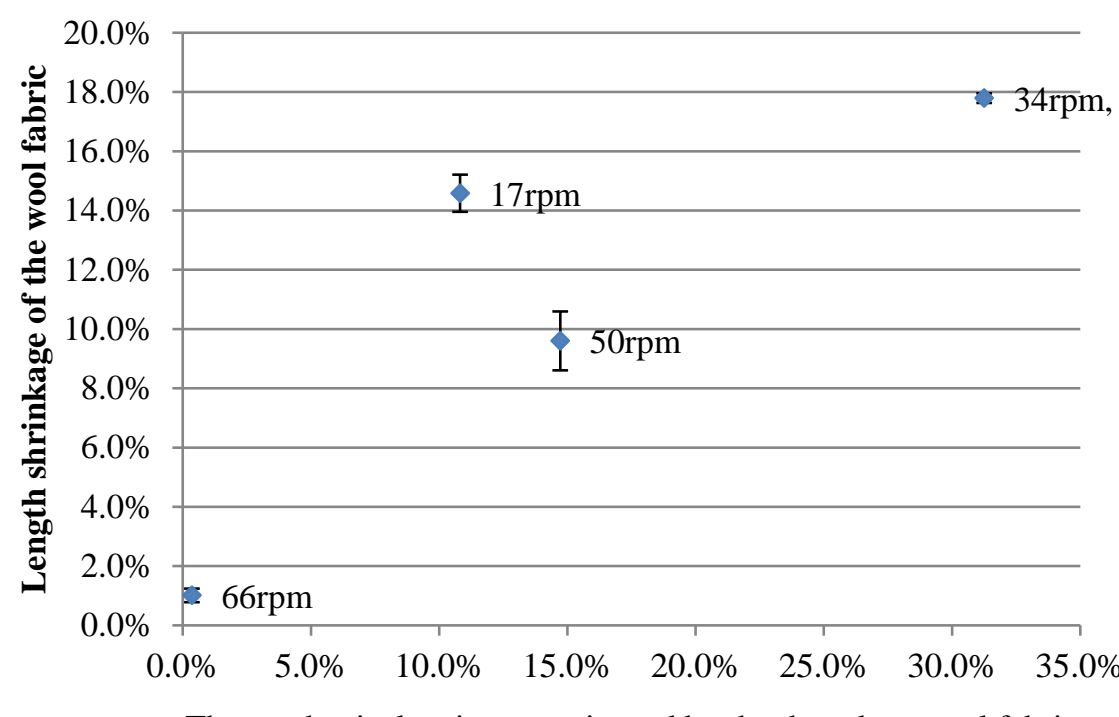

The mechanical action experienced by the thread removal fabric

Figure 7 Relationship between the length shrinkage of wool fabric and the total mechanical action.

Vertical lines indicate the standard deviations

\section{Conclusions}

Mechanical action applied on the fabric plays a significant part in the felting shrinkage of wool fabric during tumble drying. The current study investigated the influence of mechanical actions on the felting shrinkage of wool fabric in the tumble dryer.

Mechanical action applied on the fabric at varying rotation speeds depended on the fabric movements in tumble dryer. With increasing the rotation speed of the drum from $17 \mathrm{rpm}$ to $66 \mathrm{rpm}$, the circulated area of fabric movements increased. When the rotation speed of the drum reached $66 \mathrm{rpm}$, the fabric sample adhered to the drum wall and rotated with the drum, so little impacting or rubbing on the fabric occurred. With reducing the rotation speed of the drum lower within certain limits during the tumble drying of fabrics, the total mechanical action applied on the fabrics increased. Under the low rotation speed of the drum at $17 \mathrm{rpm}$, fabrics moved in the small movement area around the corner of the drum, and the main mechanical action applied on fabrics was rubbing force. However, the main mechanical action on the fabrics at $50 \mathrm{rpm}$ drum rotation speed was the impact force. At $34 \mathrm{rpm}$ rotation speed of the tumble drum, both rubbing and impact occurred on fabrics.

From analysis of the relationship between mechanical action and felting shrinkage, it was suggested that both the severity and the type of the mechanical action influence the felting shrinkage of wool fabric. It is understandable that the more severe the 
mechanical action, the greater is the felting shrinkage of wool fabric. Impacting of the fabric to the drum wall appears to have a smaller contribution to felting shrinkage than rubbing between fabrics. For preventing wool felting shrinkage, the high rotation speed of drum could be used to make fabric adhered to the wall of the drum and rotated with the drum in the tumble dryer. However, in order to achieve both prevention of wool felting shrinkage and efficient energy use for drying wool fabrics, the fabric movement in either high speed of rotation or fabric falling movement should be further investigated to develop the potential method for drying wool fabric in drying machines.

\section{Acknowledgements}

The funding supports to this research are provided by National Key R\&D Program of China through project 2018YFF0215703, Shanghai Science and Technology Committee through project 17DZ2202900, Shanghai Summit Discipline in Design through project DD18005, the Fundamental Research Funds for the Central Universities (2232019G-08), the Institute for Nonlinear Sciences of Donghua University through project INS1901, and the China Scholarship Council.

\section{Reference}

1. Laitala K, Klepp IG and Henry B (2017) Use phase of apparel: A literature review for Life Cycle Assessment with focus on wool. Report, Consumption Research Norway, Oslo and Akershus University College of Applied Sciences. Report no. 6-2017.

2. Makinson KR. Studies of the movement of wool fibers in fabrics during felting, with particular reference to the permanency of pleats: part III: felting in a woolen fabric. Text Res $J$ 1960; 30: 598-606.

3. Moncrieff RW. Wool shrinkage and its prevention. London: The National Trade Press LTD, 1953.

4. Rippon J. Friction, felting and shrink-proofing of wool. In: Gupta BS (eds) Friction in textile materials. Cambridge: Woodhead Publishing, 2008, pp. 253-291.

5. Makinson KR. Studies of the movement of wool fibers in fabrics during felting: part IV: quantitative relations between duration of milling, shrinkage, and fiber movements. Text Res $J$ 1962; 32: 364-374.

6. Baird K and Foulds RA. Felting shrinkage of plain-knitted wool fabrics: its dependence upon fabric structure and shrinkproofing level. Text Res $J$ 1968; 38: 743-753.

7. McPhee JR. Shrink-Resist Treatment and Laundering of Wool Fabrics. Text Res J 1961; 31: 10451053. 
8. McPhee JR. Rate of felting of untreated and shrink-resistant wool fabrics. Text Res $J$ 1961; 31 : $770-778$.

9. Swanepoel O and Van Rooyen A. Machine washing of wool. Text Res J 1970; 40: 516-520.

10. Denby E. The severity of impeller washing machines. Text Res $J$ 1980; 50: 416-419.

11. Wei Y, et al. The effect of fabric movement on drying performance of the domestic drum dryer. J Text I 2019; 110: 1059-1071.

12. Bao W, et al. Dimensional change of wool fabrics in the process of a tumble-drying cycle. Text Res $J$ 2019; 89: 4702-4709.

13. Wei Y, et al. Enhancing the energy efficiency of domestic dryer by drying process optimization. Dry technol 2018; 36: 790-803.

14. Wang F, Zeng J and Ding X. Study on fabric's abrasion during home laundering. China Appliance Technology 2014; 12: 86-89.

15. Bao W, et al. Optimizing a laundering program for textiles in a front-loading washing machine and saving energy. J Clean Prod 2017; 148: 415-421.

16. Luo Z. The maximum impact force on the fabric in a tumble washing machine. Science and Technology of Household Electric Appliance 1990: 9-10.

17. Yun $\mathrm{C}$ and Park $\mathrm{CH}$. The effect of fabric movement on washing performance in a front-loading washer II: under various physical washing conditions. Text Res $J$ 2015; 85: 251-261.

18. Mac Namara C, et al. Dynamics of textile motion in a front-loading domestic washing machine. Chem Eng Sci 2012; 75: 14-27.

19. Yun $\mathrm{C}$, Cho $\mathrm{Y}$ and Park $\mathrm{CH}$, Washing efficiency and fabric damage by beating and rubbing movements in comparison with a front-loading washer. Text Res $J$ 2017; 87: 708-714. 